\title{
DNA polymorphisms of the Hu sheep melanocortin-4 receptor gene associated with birth weight and 45-day weaning weight
}

\author{
X.M. Song ${ }^{1}$, J.F. Jiang ${ }^{1}$, G.Z. Zhang ${ }^{1,2}$, F.X. Shi ${ }^{2}$ and Y.Q. Jiang ${ }^{1}$ \\ ${ }^{1}$ Institute of Animal Husbandry and Veterinary, \\ Zhejiang Academy of Agricultural Sciences, Hangzhou, China \\ ${ }^{2}$ College of Animal Science and Technology, \\ Nanjing Agricultural University, Nanjing, China \\ Corresponding authors: X.M. Song / Y.Q. Jiang \\ E-mail: songxuemei@yeah.net /.jyq61@sohu.com
}

Genet. Mol. Res. 11 (4): 4432-4441 (2012)

Received March 12, 2012

Accepted June 22, 2012

Published September 27, 2012

DOI http://dx.doi.org/10.4238/2012.September.27.3

\begin{abstract}
The melanocortin-4 receptor (MC4R) has important roles in regulating food intake, energy balance, and body weight in mammals. In pigs and cattle, MC4R mutations have been identified as genetic markers for growth and traits. Compared with abundant research conducted on other livestock species, little is known about mutations of the ovine $M C 4 R$ gene. We investigated the effect of $M C 4 R$ polymorphisms on birth weight and on 45-day weaning weight in $144 \mathrm{Hu}$ sheep. Four single nucleotide polymorphisms (SNPs; g.1016 G/A, g.1240 T/C, g.1264 G/A, and g.1325 $\mathrm{A} / \mathrm{G}$ ) were identified in the 3'-untranslated region of Hu sheep $M C 4 R$ by PCR-single-strand conformation polymorphism and DNA sequencing. A haplotype block, containing g.1240 T/C, g.1264 G/A, and g.1325 A/G, was constructed within the Hu sheep MC4R gene. Four SNPs were found to be significantly associated with 45-day weaning weight, while the haplotype block was significantly associated with birth weight. Hu sheep with the genotypes GG in g.1016 G/A or with the genotype CCAAGG in the haplotype block, had higher 45-day weaning weights. We conclude
\end{abstract}


that these 4 SNPs of the $M C 4 R$ gene have potential as genetic markers for early growth traits in Hu sheep.

Key words: $M C 4 R$ gene; Polymorphism; Early growth traits; Hu sheep

\section{INTRODUCTION}

The melanocortin-4 receptor (MC4R), a rhodopsin-like G protein-coupled receptor, is primarily expressed in the neural system and is involved in the regulation of food intake, energy balance, and body weight in mammals. Reports regarding spiny dogfish and goldfish $M C 4 R$ have demonstrated that the central melanocortin system evolved early in vertebrate evolution for the regulation of energy homeostasis, implying that $M C 4 R$ was involved in important early physiological processes (Cerda-Reverter et al., 2003a,b; Ringholm et al., 2003; Govaerts et al., 2005). Therefore, $M C 4 R$ is of considerable interest among candidate genes for controlling variation in energy metabolism and growth traits. In 2004, over 60 nucleotide variations were identified from various pig-like species separated by several million years of the evolution (Kim et al., 2004). Some of these variations appear to have been preserved during the diversification in the Sus scrofa species. The pattern of these variations provides insight into the genetic diversity of mammalian MC4R (Kim et al., 2004).

To date, 58 frame shift mutations in $M C 4 R$ significantly associated with human obesity have been reported (MacKenzie, 2006). It has been accepted that the $M C 4 R$ mutations are the most common single gene that causes non-syndromic human obesity. In livestock species, MC4R mutations have also been identified as genetic markers for growth and fatness traits (Kim et al., 2000; Haegeman et al., 2001; Bruun et al., 2006). The pig quantitative trait locus (QTL) analyses have supported the hypothesis of the MC4R gene as a positional candidate gene for the fatness and fleshiness QTL (Bruun et al., 2006).

Compared with the abundant research in human beings, pigs, dogs, and other mammals, little is reported regarding the details of the ovine MC4R gene (Lubrano-Berthelier et al., 2003a,b; Stinckens et al., 2009; Skorczyk et al., 2007, 2012). Hu sheep, a famous Chinese sheep breed, are distributed in Zhejiang and Jiangsu Provinces and the suburbs of Shanghai in China. As a result of a long process of acclimatization and artificial selection, Hu sheep are well recognized for their beautiful wavy lambskins, early sexual maturity, seasonal breeding, fast growth, prolificacy, and the adaptability to a hot and humid climate. Adult Hu sheep weights can be reached at the age of 12 months; the adult rams weigh $47-65 \mathrm{~kg}$, and adult sheep weigh 32-44 kg (Chen, 1984; Pan et al., 1987). In this study, we identified the polymorphisms of the $M C 4 R$ gene in a Hu sheep meat line used to produce heavy sheep, and evaluated their association with birth weight and 45-day weaning weight of Hu sheep.

\section{MATERIAL AND METHODS}

\section{Experimental animals}

The Hu sheep meat line was established from purebred sheep at the Yuhang Hu Sheep Breeding Farm in Hangzhou, China. Venous jugular blood samples $(10 \mathrm{~mL}$ per sheep, using acid citrate dextrose as an anticoagulant) were collected from $144 \mathrm{Hu}$ sheep. Genomic DNA 
was extracted from whole blood by the phenol-chloroform method as described by Sambrook and Russell (2001), then dissolved in TE buffer [10 mM Tris-HCl, pH 8.0, $1 \mathrm{mM}$ ethylenediaminetetraacetic acid (EDTA), $\mathrm{pH} \mathrm{8.0]} \mathrm{and} \mathrm{kept} \mathrm{at}-20^{\circ} \mathrm{C}$. The birth weight and 45-day weaning weight data from $144 \mathrm{Hu}$ sheep were recorded for further analysis.

\section{Primers, PCR amplification, genotyping, sequencing, and analysis of mutations}

One pair of primers, SMC4RF and SMC4RR, was designed according to conserved sequences of MC4R multiple sequence alignment (GenBank accession Nos. NM_001126370 and NC_007325) to amplify the full-length $M C 4 R$ gene of Hu sheep. Subsequently, 8 pairs of primers for single-strand conformation polymorphism (SSCP) were designed to detect single nucleotide polymorphisms (SNPs) in MC4R (primers listed in Table 1). All DNA variants were located by Mutation Surveyor ${ }^{\mathrm{TM}}$ v4.0.4 (SoftGenetics, LLC, State College, PA, USA).

PCR was carried out in a $25-\mu \mathrm{L}$ volume containing approximately $2.5 \mu \mathrm{L} 10 \mathrm{X}$ PCR buffer $\left(\mathrm{Mg}^{2+}\right), 200 \mu \mathrm{M}$ of each dNTP, $10 \mathrm{pM}$ of each primer, 2 U TransTaq HiFi DNA polymerase (Transgene, Beijing, China), and 50 ng sheep genomic DNA as a template. Amplification conditions were as follows: initial denaturation at $94^{\circ} \mathrm{C}$ for $3 \mathrm{~min}$ followed by 35 cycles of denaturation at $94^{\circ} \mathrm{C}$ for $30 \mathrm{~s}$, annealing at $54.8-66^{\circ} \mathrm{C}$ (listed in Table 1) for $30 \mathrm{~s}$, extension at $72^{\circ} \mathrm{C}$ for $30 \mathrm{~s}$ with extension at $72^{\circ} \mathrm{C}$ for $10 \mathrm{~min}$, then holding at $4^{\circ} \mathrm{C}$ on a Mastercycler 5333 (Eppendorf AG, Hamburg, Germany).

A 5- $\mu \mathrm{L}$ volume of PCR product was transferred to an Eppendorf tube, mixed with $10 \mu \mathrm{L}$ gel loading solution containing $98 \%$ formamide, $0.025 \%$ bromophenol blue, $0.025 \%$ xylene cyanol, $20 \mathrm{mM}$ EDTA, pH 8.0, and 10\% glycerol. The mixture was centrifuged and denatured at $99^{\circ} \mathrm{C}$ for $10 \mathrm{~min}$, then chilled on ice for $30 \mathrm{~min}$ and loaded onto $15 \%$ neutral polyacrylamide gels (acrylamide:bisacrylamide $=39: 1$ ). Electrophoresis was performed in $1 \mathrm{X}$ Tris borate-EDTA buffer, $\mathrm{pH} 8.3$, at $9-15 \mathrm{~V} / \mathrm{cm}$ at $4^{\circ} \mathrm{C}$ overnight. After electrophoresis, the DNA fragments on the gels were visualized by silver staining, then photographed. Finally, the PCR products with different electrophoresis patterns were purified for sequencing.

\section{Statistical analysis}

Gene frequencies were determined for each locus by direct counting. Allele frequencies and polymorphism information content (PIC) were derived using the Population Genetic Analysis package (POPGENE; Version 1.31; Molecular Biology and Biotechnology Centre, University of Alberta: Edmonton, Canada) (Krawczak et al., 2006). Haplotype and linkage disequilibrium (LD) block analyses were performed by HaploView version 4.2 (Whitehead Institute for Biomedical Research, Cambridge, MA, USA). The haplotype block definition was followed according to that of Gabriel et al. (2002). They define pairs to be in "strong LD" if the 1-sided upper $95 \%$ confidence bound of $\mathrm{D}^{\prime}$ is $>0.98$ (that is, consistent with no historical recombination) and the lower bound is above 0.7 .

All loci were tested for deviations from Hardy-Weinberg equilibrium by means of a standard chi-squared test. The additive effect of SNPs was estimated as the difference between the mean of the 2 homozygotes divided by 2 , and dominance was estimated as the deviation of the heterozygote from the mean of the 2 homozygotes (Falconer and Mackay, 1996).

The relationship between the different genotypes of each SNP and birth weight or 45-day 
weaning weight least squares means was evaluated using a single-marker-lined model association analysis. Data were analyzed by fitting a general linear model using the restricted maximum likelihood method in the Statistical Package for the Social Sciences (SPSS; Version 13.0; SPSS Inc., Chicago, IL, USA). The statistical analyses model included fixed effects of SNP genotype, sib number, birth weight, 45-day weaning weight, and sex traits. The following 2 fixed effects models were employed for analysis of birth weight or 45-day weaning weight in Hu sheep, and least squares means were used for multiple comparisons of birth weight or 45-day weaning weight among different genotypes. The general models used for early growth traits were as follows:

$$
\begin{array}{cc}
\mathrm{Yijkl}=\mu \mathrm{i}+\mathrm{Mj}+\mathrm{Sk}+\mathrm{Nl}+\text { eijkl } & \text { (Equation 1) } \\
\text { Yijklm }=\mu \mathrm{i}+\mathrm{Aj}+\mathrm{Dk}+\mathrm{Sl}+\mathrm{Nm}+\text { eijklm } & \text { (Equation 2) }
\end{array}
$$

where Yijkl or Yijklm is the phenotypic value of birth weight or 45-day weaning weight observed value; $\mu i$ is the least square mean; $M j$ is the fixed effect of the $\mathrm{j}^{\text {th }}$ genotype ( 3 levels); $A j$ is the fixed effect of the $\mathrm{j}^{\text {th }}$ additive effect ( 3 levels); $D k$ is the fixed effect of the $\mathrm{k}^{\text {th }}$ dominance effect (2 levels); $\mathrm{Sk}$ or $\mathrm{Sl}$ is the fixed effect of sex (2 levels); $\mathrm{Nl}$ or $\mathrm{Nm}$ is the effect of sib number (4 levels); eijk or eijklm is the random residual effect of each observation. $A j=-0.5$, 0 , or 0.5 if individual $j$ has genotype $\mathrm{AA}, \mathrm{AB}$, or $\mathrm{BB}$, and $D k=1$ (or -0.5 ) if individual $i$ has genotype $\mathrm{AB}$ (or others).

\section{RESULTS}

\section{PCR-SSCP analysis and genetic polymorphism of the Hu sheep MC4R gene}

To identify Hu sheep homolog of the MC4R gene, multiple alignments of sheep (GenBank accession No. NM_001126370) and cow (GenBank accession No. NC_007325) MC4R sequences were carried out (data not shown). Primer pair SMC4R (Table 1) was designed from the conserved regions to amplify the partial sequence of $M C 4 R$ from genomic DNA of $\mathrm{Hu}$ sheep. The amplified products with the expected size were purified and sequenced. Sequence analysis showed that the sequence from Hu sheep (submitted to the National Center for Biotechnology Information (NCBI), GenBank accession No. JQ710684) had high identity with sheep and cow $M C 4 R$ sequences ( 99 and $94 \%$, respectively), indicating that the obtained sequence was the $M C 4 R$ sequence of Hu sheep.

To detect polymorphisms of Hu sheep $M C 4 R, 8$ primer pairs (M1-M8) were designed for SSCP analysis. Three genotypes were found when primer pair M6 or M7 was used, but not with other primer pairs, and these genotypes were used for amplification (Figure 1). Among the 3 genotypes, the homozygote $\mathrm{AA} / \mathrm{CC}$ was defined as the wild genotype, $\mathrm{BB} / \mathrm{DD}$ as the mutation genotype, while $\mathrm{AB} / \mathrm{CD}$ was the heterozygous genotype. Each fragment was sequenced and the sequences were analyzed with Mutation Surveyor ${ }^{\mathrm{TM}}$ (SoftGenetics, LLC, State College, PA, USA). The results indicated that 4 polymorphisms appeared in the Hu sheep $M C 4 R$ gene, and all of them were in the MC4R 3'-untranslated region (UTR; Table 2). A G $\rightarrow$ A mutation, located at +1016 (the first nucleotide of the coding region of the $M C 4 R$ gene is defined as +1 ), was found in the PCR fragment amplified by primer pair M6. Three polymorphisms, $\mathrm{T} \rightarrow \mathrm{C}$ mutation at $+1240, \mathrm{G} \rightarrow \mathrm{A}$ mutation at +1264 , and $\mathrm{A} \rightarrow \mathrm{G}$ mutation at +1325 , were found in the PCR fragments amplified by primer pair M7. 
Table 1. Primers used for sequencing and genotyping the Hu sheep $M C 4 R$ gene.

\begin{tabular}{|c|c|c|c|c|}
\hline Name & Sequence $\left(5^{\prime} \rightarrow 3^{\prime}\right)$ & Location & Size of PCR products (bp) & Annealing temperature $\left({ }^{\circ} \mathrm{C}\right)$ \\
\hline SMC4R & F: 5'-GCCTAAGATTTCCAAGTGATGCTGA-3' & $-211-1546$ & 1765 & 60.0 \\
\hline M1 & $\begin{array}{l}\text { F: 5'-GCCTAAGATTTCCAAGTGATGCCGA-3' } \\
\text { R: 5'-AGGAGTGGAGAGAGGTGTGCAT-3' }\end{array}$ & $-211-46$ & 257 & 60.0 \\
\hline M2 & $\begin{array}{l}\text { F: 5'-GAATCCAAAATGAACTCTACCCAGC-3' } \\
\text { R: 5'-TGAGTGCAGATTCTTGTTCTTGGC-3' }\end{array}$ & $-9-231$ & 240 & 54.8 \\
\hline M3 & $\begin{array}{l}\text { F: 5'-GGAGAATATTCTGGTGATCGTGGC-3' } \\
\text { R: 5'-GTGAAGTACCTGTCCACCGCGAT-3' }\end{array}$ & $180-449$ & 270 & 57.5 \\
\hline M4 & $\begin{array}{l}\text { F: 5'-CATTGACTCGGTGATCTGTAGCTC-3' } \\
\text { R: 5'-GGAACATGTGGACATAGAGAGACG-3' }\end{array}$ & $372-649$ & 278 & 66.0 \\
\hline M5 & $\begin{array}{l}\text { F: 5'-CATCTGCCTCATCACCGTGTTCTT-3' } \\
\text { R: 5'-CGATGACAGAATTACACATGATCAGG-3' }\end{array}$ & $582-892$ & 311 & 64.2 \\
\hline M6 & $\begin{array}{l}\text { F: 5'-CCTGCACCTGATATTCTACATCTC-3' } \\
\text { R: 5'-GTACACATGAGAAGGAGAAGGTC-3' }\end{array}$ & $786-1059$ & 274 & 62.2 \\
\hline M7 & $\begin{array}{l}\text { F: 5'-GCGATGCCAAACACAAGCTTAA-3' } \\
\text { R: 5'-CTGTCACACCCTTGTAAATCAC-3' }\end{array}$ & $1013-1333$ & 321 & 62.2 \\
\hline M8 & $\begin{array}{l}\text { F: 5'-CTCATCACAGGTTACAGGCACT-3' } \\
\text { R: 5'-CTGCACAGGAAGAATGAATGAG-3' }\end{array}$ & $1226-1546$ & 321 & 64.2 \\
\hline
\end{tabular}

\section{A}

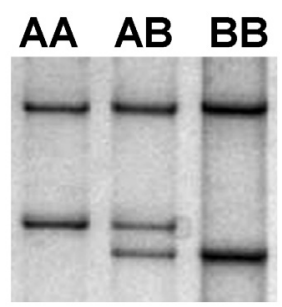

B

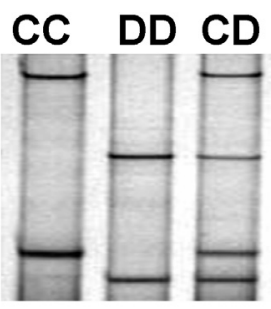

Figure 1. PCR-SSCP analysis of M6 and M7 primer pairs on a silver-stained gel. A. Represents the analysis of M6 primer pair. B. Represents the analysis of M7 primer pair. The observed SSCP alleles are indicated on the top.

Table 2. Sequence comparison among different genotypes.

\begin{tabular}{lclcc}
\hline Primers & Genotype & Nucleotide sequence & Location of mutation & Change of nucleotide \\
\hline M6 & AA & acaaactgcgGtgccaaacac & +1016 & $\mathrm{G} \rightarrow \mathrm{A}$ \\
& BB & acaaactgcgAtgccaaacac & & \\
M7 & CC & ggttaTaggcactatggatttataaaaaGaaaaa; atttacaaggAtgtgacactt & +1240 & $\mathrm{~T} \rightarrow \mathrm{C}$ \\
& DD & ggttaCaggcactatggattataaaaaAaaaaa; atttacaaggGtgtgacactt & +1264 & $\mathrm{G} \rightarrow \mathrm{A}$ \\
& & & +1325 & $\mathrm{~A} \rightarrow \mathrm{G}$ \\
\hline
\end{tabular}

Capital letters in bold represent mutations in the sequence.

To determine the genetic characteristics of polymorphisms of the Hu sheep MC4R gene, we calculated the genotypic frequencies, allelic frequencies, and PIC of 4 SNPs in the Hu sheep meat line population. The results are presented in Table 3, which revealed that, in the $\mathrm{Hu}$ sheep meat line population, allele A at +1016 locus, and allele TGA at $+1240,+1264$, and +1325 , respectively, were the predominant alleles, which were consistent with the predominant genotypes in the 4 loci. The results of PIC of the 4 loci indicated that the 4 SNPs should be considered as moderate polymorphisms (Table 3). Moreover, the genotype frequencies at all 4 SNPs were in agreement with Hardy-Weinberg equilibrium. 
Table 3. Frequencies of genotypes and alleles of the Hu sheep MC4R gene.

\begin{tabular}{llclcc}
\hline Polymorphism & Genotypes & Genotypic frequencies & Alleles & Allelic frequencies & PIC \\
\hline g.1016 G/A & GG (10) & 0.0694 & G & 0.2639 & 0.3130 \\
& GA (56) & 0.3889 & & & \\
& AA (78) & 0.5417 & A & 0.7361 & 0.3169 \\
g.1240 T/C & TTGGAA (78) & 0.5417 & TGA & 0.7292 & \\
g.1264 G/A & TCGAAG (54) & 0.3750 & & 0.2708 & \\
g.1325 A/G & CCAAGG (12) & 0.0833 & CAG & 0.270 \\
\hline
\end{tabular}

$\mathrm{PIC}=$ polymorphic information content.

\section{Intra-MC4R linkage disequilibrium}

To understand the intra-MC4R LD of the 4 SNPs, $\mathrm{D}^{\prime}, \mathrm{r}^{2}$ and log odds (LOD) scores were estimated for each pair of SNPs in Haploview. The results are shown in the schematic Figure 2, where the red diamonds indicate strong LD between pairs of SNPs $\left(\mathrm{D}^{\prime}>0.8\right)$ with statistical significance (LOD score >2.0; Barrett et al., 2005). Four SNPs in $M C 4 R$ were found to be in LD with $\mathrm{D}^{\prime}$ above 0.75 for each SNP pair combination. Further, $\mathrm{r}^{2}$ values between each pair of MC4R SNPs were above 0.5612, while the value between the 3 SNPs in the haplotype block, containing g.1240 T/C, g.1264 G/A, and g.1325 A/G, was 1.

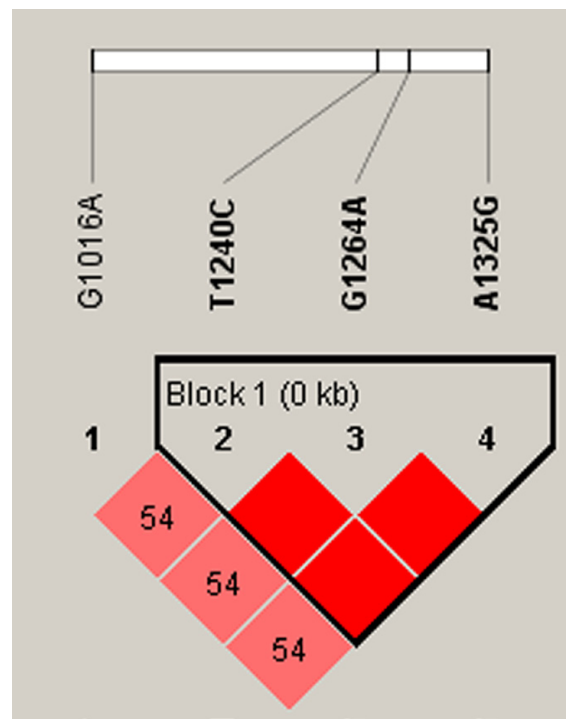

Figure 2. Linkage disequilibrium (LD) analyses in the Hu sheep $M C 4 R$ gene. Pair-wise LD was noted based on $\mathrm{r}^{2}$ measurement (number inside the squares).

\section{Least squares mean and standard error for birth weight or 45-day weaning weight of different $M C 4 R$ genotypes in Hu sheep}

To investigate the effects of $\mathrm{Hu}$ sheep $M C 4 R$ polymorphisms, we analyzed the rela- 
tionship between $M C 4 R$ genotypes and their effects on birth weight or weaning weight. The least squares mean and standard error for birth weight or weaning weight of different $M C 4 R$ genotypes in the Hu sheep meat line were calculated with a general linear model (Table 4). The sheep with the GG genotype at +1016 showed higher weaning weight $(17.87 \pm 2.431 \mathrm{~kg})$ in comparison to the sheep with the AA $(14.51 \pm 2.214 \mathrm{~kg})$ or GA $(14.78 \pm 1.964 \mathrm{~kg})$ genotypes $(\mathrm{P}$ $<0.01$; Table 4); however, the weaning weight of GA and AA genotype sheep showed no significant difference $(\mathrm{P}>0.05)$. These results indicated that the sheep with the GG genotype had a tendency to gain more birth weight or weaning weight than the sheep with GA or AA genotypes. In other words, $1016 \mathrm{G}$ might be the beneficial allele for birth weight or weaning weight. Regarding the haplotype block, the homozygous mutant sheep showed higher weaning weight (17.81 $\pm 2.172 \mathrm{~kg})$ relative to the homozygous wild-type $(14.44 \pm 2.230 \mathrm{~kg})$ or heterozygous mutant $(14.70 \pm 1.841 \mathrm{~kg})$ sheep $(\mathrm{P}<0.01$; Table 4$)$; the weaning weight of homozygous wild-type and heterozygous mutant sheep were not significantly different $(\mathrm{P}<0.05)$. These results indicated that homozygous mutant sheep had a tendency to gain more birth weight or weaning weight than the homozygous wild-type or heterozygous mutant sheep; the mutant allele in the MC4R 3'-UTR haplotype block might be a beneficial allele for birth weight or weaning weight.

\begin{tabular}{|c|c|c|c|c|c|c|c|}
\hline & \multirow{2}{*}{$\begin{array}{c}\text { SNP } \\
\text { g.1016 G/A }\end{array}$} & \multicolumn{3}{|c|}{ Genotype means $\pm \mathrm{SE}$} & \multirow[t]{2}{*}{ Overall Pa } & \multirow{2}{*}{$\begin{array}{c}\text { Addictive } \\
\text { effect } \pm \mathrm{SE}^{\mathrm{b}}\end{array}$} & \multirow{2}{*}{$\begin{array}{c}\text { Domain } \\
\text { effect } \pm \mathrm{SE}^{\mathrm{c}}\end{array}$} \\
\hline & & GG & GA & AA & & & \\
\hline $\begin{array}{l}\text { Birth weight }(\mathrm{kg}) \\
\text { 45-day weaning weight }(\mathrm{kg})\end{array}$ & & $\begin{array}{c}3.550 \pm 0.946 \\
17.871 \pm 2.431^{* *}\end{array}$ & $\begin{array}{r}3.072 \pm 0.747 \\
14.776 \pm 1.964\end{array}$ & $\begin{array}{r}3.096 \pm 0.685 \\
14.512 \pm 2.214\end{array}$ & $\begin{array}{l}0.270 \\
0.001\end{array}$ & $\begin{array}{l}0.226 \pm 0.145 \\
1.680 \pm 0.431^{* *}\end{array}$ & $\begin{array}{l}-0.251 \pm 0.197 \\
-1.416 \pm 0.588\end{array}$ \\
\hline & $\begin{array}{l}\text { g. } 1240 \mathrm{~T} / \mathrm{C} \\
\text { g. } 1264 \mathrm{G} / \mathrm{A} \\
\text { g. } 1325 \mathrm{~A} / \mathrm{G}\end{array}$ & TTGGAA & TCGAAG & CCAAGG & & & \\
\hline Birth weight (kg) & & $3.005 \pm 0.699$ & $3.135 \pm 0.654^{*}$ & $3.828 \pm 0.960^{* *}$ & $* 0.006$ & $-0.411 \pm 0.125^{*}$ & $-0.282 \pm 0.178$ \\
\hline 45-day weaning weight $(\mathrm{kg})$ & & $14.440 \pm 2.230$ & $14.697 \pm 1.841$ & $17.811 \pm 2.172^{* *}$ & * 0.000 & $-1.685 \pm 0.379^{* *}$ & $-1.429 \pm 0.540$ \\
\hline
\end{tabular}

According to the definition presented by Falconer and Mackay (1996), the genetic effects of different $M C 4 R$ genotypes analyzed by a general linear model (Equation 2) are summarized in Table 4. An additive effect was significant or extremely significant at 4 loci, but there was no significant dominance effect. Furthermore, the dominant gene effect was negative, which indicated negative heterosis. The homozygous wild-type allele of $1016 \mathrm{G}$ and the mutant allele in the haplotype block were significantly associated with an increase in 45-day weaning weight. All absolute values of the additive effect were higher than those of the dominant effect, with the exception of the birth weight of g.1016 G/A. These results indicated that the genetic loci characteristics agreed with the additive-dominance model, and the additive gene effect played a more important role than the dominant gene effect.

\section{DISCUSSION}

Hu sheep originated from Mongolian sheep; as early as the time of the Song Dynasty 
(420-479 A.D.), Mongolian sheep were introduced from the pastoral region of North China to the Taihu Lake basin that borders the present Provinces of Zhejiang and Jiangsu. As a result of a long process of acclimatization and artificial selection, Hu sheep grow quickly, thus the primary objective of this study was to identify the associations between $M C 4 R$ SNPs and early growth traits. In the present study, by PCR-SSCP and DNA sequencing, we characterized the 3'-UTR mutations of the $M C 4 R$ gene in Hu sheep for the first time.

In humans, MC4R represents a compelling biological candidate underlying obesity, as rare coding mutations in the gene are the leading cause of the most common known monogenic obesity disorder (Farooqi et al., 2000). Fifty-eight mutations in the coding sequence (2400 bp) of the human MC4R gene have been demonstrated to be associated with obesity pathogenicity (MacKenzie, 2006). Therefore, this gene has been studied in various mammals, including pig (Kim et al., 2004), cattle (Huang et al., 2010; Liu et al., 2010), dog, and red fox (Skorczyk et al., 2007). Furthermore, the association of MC4R variants with obesity-related quantitative traits has also been extensively studied in many mammals. Several reports presented strong evidence of associations between a porcine $M C 4 R$ missense mutation, Asp298Asn, and some obesity-related traits, such as fatness, growth rate, and feed intake (Kim et al., 2000; Hernandez-Sanchez et al., 2003; Kim et al., 2004; Jokubka et al., 2006). SNPs of MC4R genes associated with growth traits in cattle were also detected (Zhang et al., 2009). In our study, we reported 4 SNPs in the sheep $M C 4 R$ gene 3'-UTR (300 bp) for the first time, and demonstrated their significant associations with birth weight and 45-day weaning weight in $\mathrm{Hu}$ sheep, which supported the possibility that MC4R SNPs detection could be applied in practical breeding to choose fast-growing individuals to satisfy particular customer requirements.

The 3'-UTR is known to play crucial roles in the post-transcriptional regulation of gene expression, including its nucleo-cytoplasmic transport (Kohler and Hurt, 2007), stability (Borrmann et al., 2001; Kamiyama et al., 2007), translation efficiency (Kindler et al., 2005; Piccone et al., 2009), and subcellular localization (Narsai et al., 2007; Thomsen et al., 2010). Moreover, the binding sequence of molecular regulator miRNA is more often located in the 3'-UTR (Grillo et al., 2010). Hence, we suppose that the mutations in the 3'-UTR of the MC4R gene might modulate the gene expression level by a mechanism that should be addressed further.

\section{ACKNOWLEDGMENTS}

Research supported by the Key Scientific \& Technological Project of the Zhejiang Province (\#2006C12014-1) and the Key Projects in the National Science \& Technology Pillar Program during the Eleventh Five-Year Plan of China (\#2008BADB2B04-7).

\section{REFERENCES}

Barrett JC, Fry B, Maller J and Daly MJ (2005). Haploview: analysis and visualization of LD and haplotype maps. Bioinformatics 21: 263-265.

Borrmann L, Wilkening S and Bullerdiek J (2001). The expression of HMGA genes is regulated by their 3'UTR. Oncogene 20: 4537-4541.

Bruun CS, Jorgensen CB, Nielsen VH, Andersson L, et al. (2006). Evaluation of the porcine melanocortin 4 receptor $(M C 4 R)$ gene as a positional candidate for a fatness QTL in a cross between Landrace and Hampshire. Anim. Genet. 37: 359-362.

Cerda-Reverter JM, Ling MK, Schioth HB and Peter RE (2003a). Molecular cloning, characterization and brain mapping of the melanocortin 5 receptor in the goldfish. J. Neurochem. 87: 1354-1367. 
Cerda-Reverter JM, Ringholm A, Schioth HB and Peter RE (2003b). Molecular cloning, pharmacological characterization, and brain mapping of the melanocortin 4 receptor in the goldfish: involvement in the control of food intake. Endocrinology 144: 2336-2349.

Chen R (1984). The Production of Hu Sheep (Chinese). 1st edn. Shanghai Science and Technology Publisher, Shanghai.

Falconer DS and Mackay TFC (1996). Introduction to Quantitative Genetics. 4th edn. Longman Scientific and Technical, New York.

Farooqi IS, Yeo GS, Keogh JM, Aminian S, et al. (2000). Dominant and recessive inheritance of morbid obesity associated with melanocortin 4 receptor deficiency. J. Clin. Invest. 106: 271-279.

Gabriel SB, Schaffner SF, Nguyen H, Moore JM, et al. (2002). The structure of haplotype blocks in the human genome. Science 296: 2225-2229.

Govaerts C, Srinivasan S, Shapiro A, Zhang S, et al. (2005). Obesity-associated mutations in the melanocortin 4 receptor provide novel insights into its function. Peptides 26: 1909-1919.

Grillo G, Turi A, Licciulli F, Mignone F, et al. (2010). UTRdb and UTRsite (RELEASE 2010): a collection of sequences and regulatory motifs of the untranslated regions of eukaryotic mRNAs. Nucleic Acids Res. 38: D75-D80.

Haegeman A, Coopman F, Jacobs K, Mattheeuws M, et al. (2001). Bovine melanocortin receptor 4: cDNA sequence, polymorphisms and mapping. Anim. Genet. 32: 189-192.

Hernandez-Sanchez J, Visscher P, Plastow G and Haley C (2003). Candidate gene analysis for quantitative traits using the transmission disequilibrium test: the example of the melanocortin 4-receptor in pigs. Genetics 164: 637-644.

Huang M, Gao X, Li JY, Ren HY, et al. (2010). Polymorphisms in MC4R gene and correlations with economic traits in cattle. Mol. Biol. Rep. 37: 3941-3944.

Jokubka R, Maak S, Kerziene S and Swalve HH (2006). Association of a melanocortin 4 receptor (MC4R) polymorphism with performance traits in Lithuanian White pigs. J. Anim. Breed. Genet. 123: 17-22.

Kamiyama M, Kobayashi M, Araki S, Iida A, et al. (2007). Polymorphisms in the 3' UTR in the neurocalcin delta gene affect mRNA stability, and confer susceptibility to diabetic nephropathy. Hum. Genet. 122: 397-407.

Kim KS, Larsen N, Short T, Plastow G, et al. (2000). A missense variant of the porcine melanocortin-4 receptor $(M C 4 R)$ gene is associated with fatness, growth, and feed intake traits. Mamm. Genome 11: 131-135.

Kim KS, Reecy JM, Hsu WH, Anderson LL, et al. (2004). Functional and phylogenetic analyses of a melanocortin-4 receptor mutation in domestic pigs. Domest. Anim. Endocrinol. 26: 75-86.

Kindler S, Wang H, Richter D and Tiedge H (2005). RNA transport and local control of translation. Annu. Rev. Cell Dev. Biol. 21: 223-245.

Kohler A and Hurt E (2007). Exporting RNA from the nucleus to the cytoplasm. Nat. Rev Mol. Cell Biol. 8: 761-773.

Krawczak M, Nikolaus S, von Eberstein H, Croucher PJ, et al. (2006). PopGen: population-based recruitment of patients and controls for the analysis of complex genotype-phenotype relationships. Community Genet. 9: 55-61.

Liu H, Tian W, Zan L, Wang H, et al. (2010). Mutations of $M C 4 R$ gene and its association with economic traits in Qinchuan cattle. Mol. Biol. Rep. 37: 535-540.

Lubrano-Berthelier C, Cavazos M, Dubern B, Shapiro A, et al. (2003a). Molecular genetics of human obesity-associated MC4R mutations. Ann. N. Y. Acad. Sci. 994: 49-57.

Lubrano-Berthelier C, Cavazos M, Le Stunff C, Haas K, et al. (2003b). The human MC4R promoter: characterization and role in obesity. Diabetes 52: 2996-3000.

MacKenzie RG (2006). Obesity-associated mutations in the human melanocortin-4 receptor gene. Peptides 27: 395-403.

Narsai R, Howell KA, Millar AH, O'Toole N, et al. (2007). Genome-wide analysis of mRNA decay rates and their determinants in Arabidopsis thaliana. Plant Cell 19: 3418-3436.

Pan X, Lu BG and Kong PL (1987). Jiangsu Livestock and Poultry Breeds (Chinese). Jiangsu Scientific and Technical Publishers, Nanjing.

Piccone ME, Pauszek S, Pacheco J, Rieder E, et al. (2009). Molecular characterization of a foot-and-mouth disease virus containing a 57-nucleotide insertion in the 3'untranslated region. Arch. Virol. 154: 671-676.

Ringholm A, Klovins J, Fredriksson R, Poliakova N, et al. (2003). Presence of melanocortin (MC4) receptor in spiny dogfish suggests an ancient vertebrate origin of central melanocortin system. Eur. J. Biochem. 270: 213-221.

Sambrook J and Russell DW (2001). Molecular Cloning: A Laboratory Manual. Cold Spring Harbor Laboratory Press, Cold Spring Harbor.

Skorczyk A, Stachowiak M, Szczerbal I, Klukowska-Roetzler J, et al. (2007). Polymorphism and chromosomal location of the MC4R (melanocortin-4 receptor) gene in the dog and red fox. Gene 392: 247-252.

Skorczyk A, Flisikowski K and Switonski M (2012). A comparative analysis of MC4R gene sequence, polymorphism, and chromosomal localization in Chinese raccoon dog and Arctic fox. DNA Cell Biol. 31: 732-738.

Stinckens A, Luyten T, Van den Maagdenberg K, Janssens S, et al. (2009). Interactions between genes involved in growth and muscularity in pigs: IGF-2, myostatin, ryanodine receptor 1, and melanocortin-4 receptor. Domest. Anim.

Genetics and Molecular Research 11 (4): 4432-4441 (2012) 
Endocrinol. 37: 227-235.

Thomsen S, Anders S, Janga SC, Huber W, et al. (2010). Genome-wide analysis of mRNA decay patterns during early Drosophila development. Genome Biol. 11: R93.

Zhang CL, Wang YH, Chen H, Lan XY, et al. (2009). Association between variants in the 5'-untranslated region of the bovine MC4R gene and two growth traits in Nanyang cattle. Mol. Biol. Rep. 36: 1839-1843. 